\title{
Application of the X-ray densitometry in the evaluation of the quality and mechanical properties of biomass pellets
}

\author{
Carolina Tenorio ${ }^{\mathrm{a}}$, Roger Moya ${ }^{\mathrm{b}, *}$, Mario Tomazello Filho $^{\mathrm{c}}$, Jorre Valaert ${ }^{\mathrm{d}}$ \\ a Instituto Tecnológico de Costa Rica, Maestría en Sistemas Modernos de Manufactura, Escuela de Ingeniería en Producción Industrial, P.O. Box: 159-7050, Cartago, Costa Rica \\ b Instituto Tecnológico de Costa Rica, Escuela de Ingeniería Forestal, P.O. Box: 159-7050, Cartago, Costa Rica \\ c Departamento de Ciências Florestais, ESALQ/Universidade de São Paulo, Av. Pádua Dias, 11-Caixa Postal 09, CEP 13418-900 Piracicaba, SP, Brazil \\ d Agrep Forestal S.A., San Carlos, Alajuela, Costa Rica
}

\section{A R T I C L E I N F O}

\section{Article history:}

Received 3 July 2014

Received in revised form 16 December 2014

Accepted 26 December 2014

Available online 12 January 2015

\section{Keywords:}

Density

Cracks

Irregularities

Clearer areas

Pellet surface uniformity

\begin{abstract}
A B S T R A C T
The use of the X-ray technique and the X-ray densitometry to determine pellet particle distribution and to understand the biomass compaction and its effects in pellet properties has been limited. The present work evaluates the quality of pellets manufactured with several lignocellulosic materials by using X-ray photography for studying surface cracks and irregularities, and by using X-ray densitometry to evaluate density and its variation in longitudinal and transversal directions. Density values and their variation were correlated to the pellets' mechanical properties (mechanical durability and compression resistance). It was found that X-ray photography may be applied to evaluate the presence of cracks and irregularities in the pellets' surface; however, these are not indicators of pellet durability or compression resistance. Moreover, density evaluation by the X-ray densitometry technique allowed the determination of the pellets' mechanical resistance and durability. A negative correlation was observed between the force at break and the coefficient of variation of density. No correlation was found between the mechanical durability and the average density or its variation. According to the above results, X-ray technique can be utilized to study the pellet quality.
\end{abstract}

@ 2014 Elsevier B.V. All rights reserved.

\section{Introduction}

Biomass is one of the most promising energy sources since it is an alternative to conventional energy sources such as petroleum and natural gas. One of its main advantages is that it's a clean and renewable product, which contributes to the reduction of greenhouse gas emission effects and of dependency on fossil fuels [1].

Today, wood residues are the main raw materials used in pellet production [2-4]. Nevertheless, agricultural residues, energetic crops and other waste products from the food industry are being used, such as: corn, oil palm residues, and some potato and tapioca varieties, among others [3-6].

Pellets present some weaknesses, among which are their mechanical resistance and compaction, which result in manipulation and durability problems [7]. Pellet quality shall depend, among other things, on the efficacy of particle bonds [8]. In consequence, many studies have been carried out to examine the effects of some variables on pellet resistance and durability [8-10].

Some techniques have been implemented to evaluate pellet quality compaction and durability-, of which scanning electron microscopy (SEM) is one of the most widely used. For example, Kaliyan and Morey

\footnotetext{
* Corresponding author.

E-mail address: rmoya@itcr.ac.cr (R. Moya).
}

[10] used this technique to determine the particles' internal distribution for different materials within the pellet. Meanwhile, Stelte et al. [3] found when using SEM, that the defects in pellets decrease particle cohesion in beech wood pellets. Furthermore, Reza et al. [11] argue that some pellets show an apparent development of a solid bridge that maintains particles joined, which makes it impossible to observe cracks in the pellet's surfaces.

Although the SEM technique is adequate to evaluate pellet quality, it has the disadvantage that it cannot be easily applied in a process. However, other techniques such as the X-ray and X-ray microCT, allow the evaluation of the material during the process instantly [12]. The X-ray technique is broadly used in diverse applications and material types. Several X-ray application methods are used for agriculture [12]. One of them is the X-ray photography, which is widely used as a tool to determine the spatial distribution of different solid phases or structures, for deformations, fatigues and fractures that result from the processing, as well as corrosion and environmental interactions [13,14].

This technique has been implemented for many years in solid wood and composite materials [15]. In solid wood for example, it is applied to determine the variability in density and ring growth [16]. In composite materials, including wooden ones such as fiberboards or particleboards, it is applied to estimate its performance [17]. It is also applied in other materials similar to wood. For example, Zhaohui et al. [18] use this same technique to determine the radial density variation profile of 
bamboo; while Belini et al. [19] use densitometry to evaluate the quality of medium density fiberboards (MDF).

However, implementing X-ray photography or X-ray densitometry to determine the distribution of pellet particles, or else to understand biomass compaction and its effects on pellet properties or briquettes, has been limited. One of the few studies was led by Ferreira et al. [20], who studied X-ray densitometry in briquettes made from wooden residues to determine whether their internal density had a homogeneous distribution, which would have an effect in briquette quality.

As a result, the present work evaluates pellet quality through visualizing the presence of surface cracks and surface pellet uniformity, and by using X-ray densitometry to determine density in twelve forestry and agricultural crops (Cupressus lusitanica, Tectona grandis, Ananas comosus, Elaeis guineensis, Arundo donax, Gynerium sagittatum, Pennisetum purpureum, Sorghum bicolor, Phyllostachys aurea, Coffea arabica and Saccharum officinarum) from Costa Rica. Likewise, density and its variability are correlated to pellet mechanical properties (durability and compression resistance) of the above-mentioned crops. These forestry and agricultural crops were chosen because they have gained popularity and technological adaptations to the pellet production process.

\section{Materials and methods}

\subsection{Materials and source}

Twelve crops growing in Costa Rica were selected to manufacture the pellets: 2 forest species and 10 agricultural crops. Table 1 presents the information for the twelve crops used. The raw materials were collected from representative area of crop plantation. A detailed description can be consulted in Aragón et al. [21] and Tenorio et al. [22].

\subsection{Pellet manufacturing process}

The pellet production process was conducted in PELLETICS S.A., in San Carlos, Alajuela province (Costa Rica). Fig. 1 presents the production process from the point where crops enter the processing plant and throughout the pellet production process. For the manufacture of pellets, the equipment and procedures already described by PELLETICS were used: the material was chipped in a JENZ chipper, model AZ 50, and later the milling was done using a fixed ring matrix with holes of $15 \mathrm{~mm}$ in diameter, KAHL brand. Afterwards, the granulate material was dried to reach 8 to $14 \%$ moisture content, using a rotary drum $\left(12 \mathrm{~m}\right.$ long $\times 3 \mathrm{~m}$ ) and air-heated to $400{ }^{\circ} \mathrm{C}$. Finally, the pelletizing process was performed in a KAHL machine, model 35780 , consisting of a fixed ring matrix of $780 \mathrm{~mm}$ in diameter, with $6 \mathrm{~mm}$ diameter and $30 \mathrm{~mm}$ long holes, with three rotating rollers, which can reach a temperature of $120{ }^{\circ} \mathrm{C}$ during the process. The particle was from 2 to $4.5 \mathrm{~mm}$. A detailed description of the process may be consulted in Aragón et al. [21].

\subsection{Pellet preparation for densitometry measurements}

The X-ray densitometry density measurement was performed in longitudinal and transversal directions (Fig. 2) on 10 randomly selected pellets for each crop. These pellets were adjusted to $12 \%$ moisture content (temperature at $22{ }^{\circ} \mathrm{C}$ and $66 \%$ relative humidity). Afterwards, weight, diameter and length of pellets were determined to calculate their actual density. For the densitometry measurement in longitudinal direction, pellet preparation was not necessary since these were placed directly in the X-ray equipment's bracket (Fig. 2a). In order to determine density in transversal direction, the 10 pellets were placed longitudinally on a base with two wooden supports (Fig. 2b), and then carefully cut into transversal sections of approximately $1.8 \mathrm{~mm}$ thick (Fig. 2c).

\subsection{Densitometrical measurements}

For the longitudinal direction measurement, 10 randomly selected pellets for each crop were placed horizontally on the bracket included with the X-ray equipment, where the X-ray source runs longitudinally through the sample. Thus, the X-ray photograph is obtained and the density profile determined. For densitometry in transversal direction, the pellet samples $1.8 \mathrm{~mm}$ thick were once again placed on the equipment's bracket to obtain the images and density readings. The exposure of the samples in longitudinal and transversal directions was performed using an X-ray scanner, from Quintek Measurement Systems Inc., QTRS-01X model. The exposure conditions were performed at $7 \mathrm{kV}$ tension in the tube, and the density readings were carried out for $1 \mathrm{~s}$ every $40 \mu \mathrm{m}$.

\subsection{Density variation and calculation by X-ray densitometry}

Firstly, the pellet's actual average density was previously determined by measuring its weight, length and diameter (Eq. (1)) on 10 randomly selected pellets for each crop. Later, X-ray densitometry was used to determine the average pellet density (Eq. (2)). The density values calculated with the X-ray equipment were corrected with the correction factor (Eq. (3)), which is calculated by the difference between the average density of all measurements obtained by densitometry (Eq. (2)) and the actual average density of the pellet.

$$
\begin{aligned}
& \text { Actual density }=\frac{\text { Pellet weight }(\mathrm{kg})}{\text { Pellet radius }\left(\mathrm{m}^{2}\right) * \text { Pellet length }(\mathrm{m}) * \pi} \\
& \text { Average density by densitometry }=\frac{\sum_{i=1}^{n} x_{i}}{n}
\end{aligned}
$$

Correction factor $=$ Average density by densitometry-Actual density

where: $x$ : density value for each measure, $n$ : number of densitometrical pellet measurements and $i$ represents the $i$ th measurements. Correction factor was determined for each pellet sampled in all crops.

Table 1

\begin{tabular}{|c|c|c|c|}
\hline Crops & Scientific name & Precedence & Abbreviation \\
\hline Sawlog residuals of $C$. lusitanica & Cupressus lusitanica & Agua Caliente, Cartago & $\mathrm{CL}$ \\
\hline Sawlog residuals of $T$. grandis & Tectona grandis & Abangares, Guanacaste & TG \\
\hline Pineapple leaves from the plant & Ananas comosus & Buenos Aires, Puntarenas & PLP \\
\hline Empty fruit bunch of the oil palm & Elaeis guineensis & Parrita, Puntarenas & EFB \\
\hline Oil palm mesocarp fiber of the fruit & Elaeis guineensis & Parrita, Puntarenas & OPMF \\
\hline Giant cane & Arundo donax & Filadelfia, Guanacaste & $\mathrm{AD}$ \\
\hline Wild cane & Gynerium sagittatum & Río Frío, Limón & GS \\
\hline King grass & Pennisetum purpureum & Paraíso, Cartago & $\mathrm{PP}$ \\
\hline Sorghum & Sorghum bicolor & Upala, Alajuela & SB \\
\hline Golden bamboo & Phyllostachys aurea & Cartago, Cartago & PA \\
\hline Coffee pulp & Coffea arabica & Tarrazú, San José & $\mathrm{CA}$ \\
\hline Sugarcane & Saccharum officinarum & San Carlos, Alajuela & so \\
\hline
\end{tabular}

Description and source of twelve crops used to manufacture pellets. 


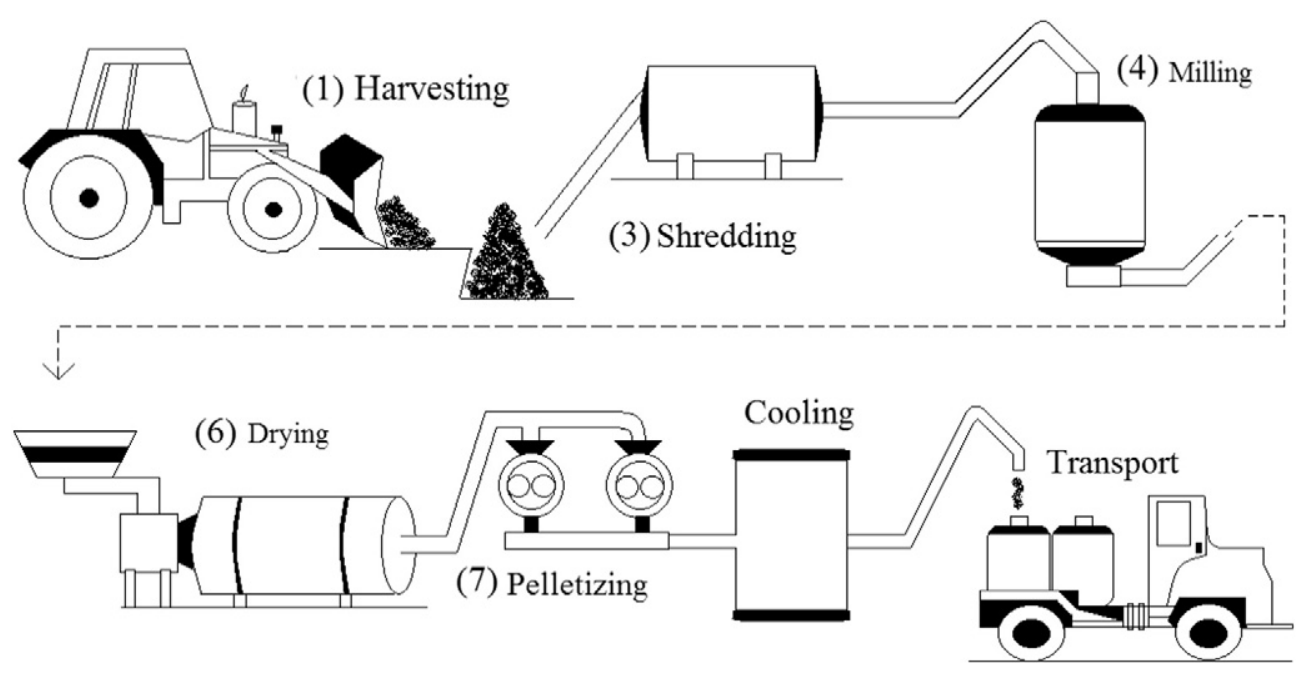

Fig. 1. Pellet manufacturing process in PELLETICS S.A. [21].

Once the correction factor was established for each pellet, it was applied to each densitometry value evaluation (Eq. (4)). The correction was applied to each pellet's values of longitudinal and transversal directions. Once the corrected density was calculated, average density (Eq. (2)) and its standard deviation (Eq. (5)) were calculated, in order to calculate the coefficient of variation (Eq. (6)) for each of the pellets for all crops evaluated. Walker and Dobb's [23] proposed methodology, which calculates the density variation in wood by using the X-ray densitometry readings, was used to calculate the coefficient of variation by means of densitometry. The coefficient of variation was determined for variation in transversal direction (CVtrans) and for variation in longitudinal direction (CVlong).

Corrected density $y_{i}=$ Density $_{i}-$ Correction factor

Standard deviation $=\sqrt{\frac{\sum\left(\text { corrected density }_{i}-\text { average corrected density }_{i}\right)^{2}}{n-1}}$

(a) Longitudinal exposure

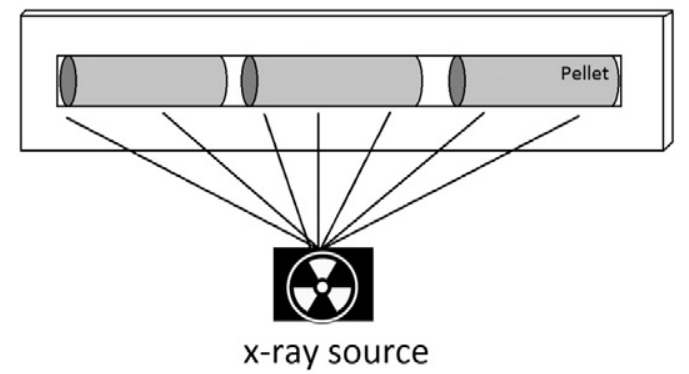

(c) Transversal exposure

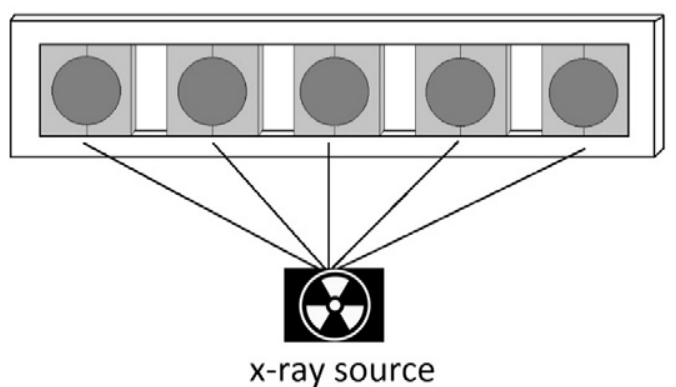
each $i$ th measurement.

\subsection{Pellet quality evaluation}

\section{(b) Obtaining transverse samples}

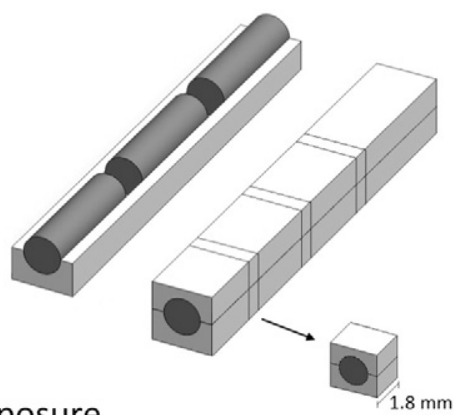

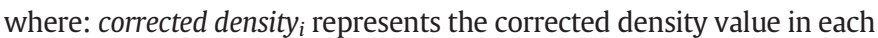
$i$ th measurement and density $y_{i}$ represents the densitometry value for

Two methods were used to evaluate pellet quality: first, the presence of pellet surface cracks and clear areas through X-ray photography was observed and second, pellet quality through the variation in density in longitudinal and transversal directions was evaluated. Clear areas were areas where layers in the pellet are separated. One area with high density usually presents density values with values over $1300 \mathrm{~kg} / \mathrm{m}^{3}$ : Ten pellets for each crop were randomly selected for both quality evaluation techniques. X-ray photographs were taken with Hewlett Packard equipment, model Faxitron LX-60 with a $12 \mathrm{~cm}$ distance between the X-ray source 
and the samples. The exposure conditions were of $15 \mathrm{~s}$ at a tension of $30 \mathrm{kV}$ within the tube.

The number of cracks present in each pellet was determined using X-ray digital images for 10 pellets and the quantity of cracks reported as frequency in relation to pellet length (cracks/mm). For clear areas, the images were analyzed by ImageJ software (National Institute of Mental Health, Bethesda, Maryland, USA). The digital image in TIFF format is filled to a threshold equal to 208. Then areas with color higher than 208 were used to represent a region with high density. These regions were compared in relation to their frequency (quantity $/ \mathrm{mm}^{2}$ ) and percentage of area with high density in relation of total area of pellet and named clear area. To evaluate quality regarding the variation of density using densitometry, $\mathrm{x}-\mathrm{y}$ graphics were created in order to show the density profiles both longitudinally and transversally.

\subsection{Determination of the mechanical properties}

The mechanical durability and compression resistance of pellets were determined. Mechanical durability is a measure of the friability of the pellets and its unit is percentage and compression test refers to both the impact and compressive resistance of pellet. To calculate the mechanical durability, the DD CENT/TS 15210-1:2005 [24] standard was applied. For this essay, 10 representative samples of $500 \mathrm{~g}$ of pellets were taken, and were passed through a sieve with a $3.36 \mathrm{~mm}$ mesh to eliminate fine particles. The sieved samples were placed in the equipment proposed by the standard at a speed of $50 \mathrm{rpm}$ for $10 \mathrm{~min}$. Afterwards the sample was removed, then sieved and weighed. Durability was calculated using Eq. (7).

For the compression resistance test 10 pellets of approximately $13 \mathrm{~mm}$ long were selected randomly. This test was performed longitudinally according to the methodology proposed by Aarseth and Prestlokken [25], by using a universal testing machine Tinus Olsen H10KT Model of 1 ton. In this test, a load velocity of $0.02 \mathrm{~mm} / \mathrm{s}$ is applied. It provides force at break vs. pellet deformation measurements, with which the maximum stress was calculated (Eq. (8)). The pellet's force at break and maximum compression stress were reported.

Mechanical durability $(\%)=\frac{\text { pellet weight after test }(\mathrm{g})}{\text { pellet weight before test }(\mathrm{g})} \times 100$

Compression stress $=\frac{2 \times \text { maximum load }(\mathrm{kg})}{\pi \times \text { Diameter }(\mathrm{cm}) \times \text { Length }(\mathrm{cm})}$

\subsection{Statistical analysis}

A descriptive analysis was carried out (median, standard deviation, maximum and minimum values) of the average longitudinal and transversal density values for each test: densitometry, mechanical durability, force at break and compression stress. In addition, the variables were verified against the normal distribution premises, variance homogeneity, and presence of extreme data. A variance analysis was applied to verify the existence of significant differences between variable averages $(\mathrm{P}<0.05)$, whereas Tukey's test was done to determine the statistical differences among crops for the medians of each of the previously mentioned values.

Pearson's correlation matrix was used to determine the correlation between density values (average, CVtrans and CVlong) and the mechanical properties studied (durability and force at break). Later, a forward stepwise multiple regression analysis was applied to determine the influence of average densities, CVtrans and CVlong, on the mechanical durability and the force at break. Then, a scatter plot graph was generated for the correlation between the force at break and density variables that were affected significantly, according to the forward stepwise regression analysis. Lastly, the variance analysis, Tukey's test and correlation analysis were performed using SAS software.

\section{Results and discussion}

\subsection{Pellet quality}

The first quality evaluation technique of X-ray photography revealed the presence of cracks (Table 2), as well as clearer areas and irregularities on the surface of pellets (Fig. 3). The evaluation of these 3 aspects in each of the species studied revealed that those pellets manufactured with OPMF, EFB and PP did not have surface cracks (Fig. 4d-e, h) or presented the lowest values (Table 2). CA and SO had few cracks (Fig. 4k-1). PLP, AD, TG and SB had few and not very deep cracks (Fig. 4c, f, l). CL, GS and PA pellets were observed to have a higher amount of deep cracks (Fig. 4a, f-g). With regard to clearer areas on the pellet's surface, these are more abundant in PLP, OPMF and AD (Fig. 4c, e, f), followed by TG and PP (Fig. 4b, h), afterwards EFB and GS (Fig. 4d, h) and lastly, CL, $\mathrm{SB}, \mathrm{CA}$ and SO (Table 2 ) hardly present any (Fig. $4 \mathrm{a}, \mathrm{k}, \mathrm{i}, \mathrm{l}$ ). The pellet surface irregularities evaluated were observed in: $C L, T G, O P M F, A D, S B, P A$ and SO (Fig. 4a-c, e, i, j and l) and were not observed in: PLP, EFB, GS, PP and CA (Fig. 4c-d, g-h, k).

The surface cracks observed represent the openings in between the compacted layers of the pellets. These cracks are produced by abrasion, which tends to remove the dust and fine material on the pellet surface, which are a consequence of the pellet manufacturing process (pelleting and cooling), of storage or compaction, or of movement during transportation, among others [26]. However, two factors tend to be related with the pellet's superficial quality (cracks and irregularities): (i) moisture content of the material prior to pelleting [2,5,27] and (ii) size and distribution of pellet particles [2,27]. Fasina [2] mentions that material humidity during pelleting strengthens particle bonds, although when moisture content is not appropriate, the capillary attraction of particles decreases, resulting in a poor union in the pellet structure, which leads to surface cracks. With respect to particle size, Payne [28] indicates that thicker particles tend to produce less durable pellets with surface cracks and irregularities; therefore, finely grounded and medium-sized particles are essential to ensure pellet quality. Likewise, Mani et al. [27] note that wooden pellets made of fine particles achieved better quality results, when compared to pellets made with thick particles.

On the other hand, the presence of clearer areas is associated to regions with high density (Fig. 3b). Such regions are a product of variations in the anatomical structure of each material and the size of granulated particles. For example, PA has high fiber concentration on the external layers of the stem [29], which causes an increase in density from the inner part of the stem to the outer part [18]. Another example is given by $\mathrm{AD}$, the anatomical structure of which varies in nodes and internodes, where the fiber wall thickness of the nodes is greater, and therefore denser [30]. This variation in crops' anatomical structure and the presence of denser parts in the plants result in some particles being placed randomly during compaction in certain areas of the pellet;

Table 2

Parameter characteristics of cracks and clear zones in surface pellet in five agricultural crops in Costa Rica.

\begin{tabular}{lcr}
\hline Agricultural crops & Cracks/mm & Clear areas/mm \\
\hline Cupressus lusitanica-CL & $4.32^{\mathrm{B}}(11.49)$ & $1.43^{\mathrm{D}}(10.61)$ \\
Tectona grandis-TG & $2.50^{\mathrm{C}}(10.93)$ & $6.28^{\mathrm{B}}(24.86)$ \\
Ananas comosus-PLP & $2.95^{\mathrm{C}}(24.50)$ & $12.97^{\mathrm{A}}(26.64)$ \\
Elaeis guineensis-EFB & $0.68^{\mathrm{E}}(16.10)$ & $3.22^{\mathrm{C}}(23.05)$ \\
Elaeis guineensis-OPMF & $0.68^{\mathrm{E}}(16.10)$ & $11.65^{\mathrm{A}}(26.00)$ \\
Arundo donax-AD & $2.95^{\mathrm{C}}(8.92)$ & $12.97^{\mathrm{A}}(23.88)$ \\
Gynerium sagittatum-GS & $5.45^{\mathrm{AB}}(6.27)$ & $2.77^{\mathrm{C}}(47.15)$ \\
Pennisetum purpureum-PP & $0.91^{\mathrm{E}}(17.48)$ & $5.28^{\mathrm{B}}(24.06)$ \\
Sorghum bicolor-SB & $2.50^{\mathrm{C}}(22.45)$ & $1.30^{\mathrm{D}}(19.20)$ \\
Phyllostachys aurea-PA & $6.14^{\mathrm{A}}(5.53)$ & $1.43^{\mathrm{D}}(16.23)$ \\
Coffea arabica-CA & $1.36^{\mathrm{D}}(22.45)$ & $1.37^{\mathrm{D}}(40.35)$ \\
Saccharum officinarum-SO & $1.36^{\mathrm{D}}(14.05)$ & $1.21^{\mathrm{D}}(17.09)$ \\
\hline
\end{tabular}

Note: Different letters for each parameter mean statistical differences significant at 95\%. 


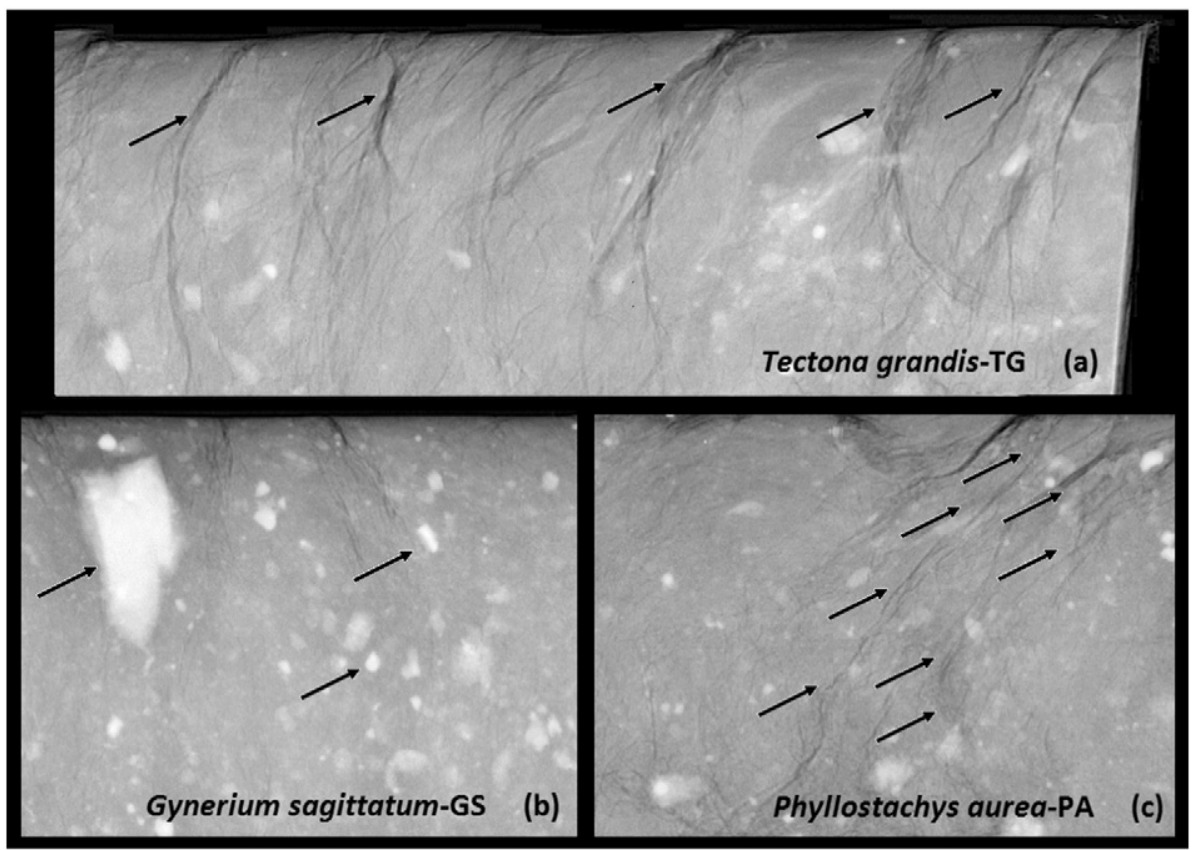

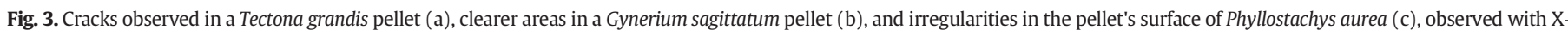
ray photographs.

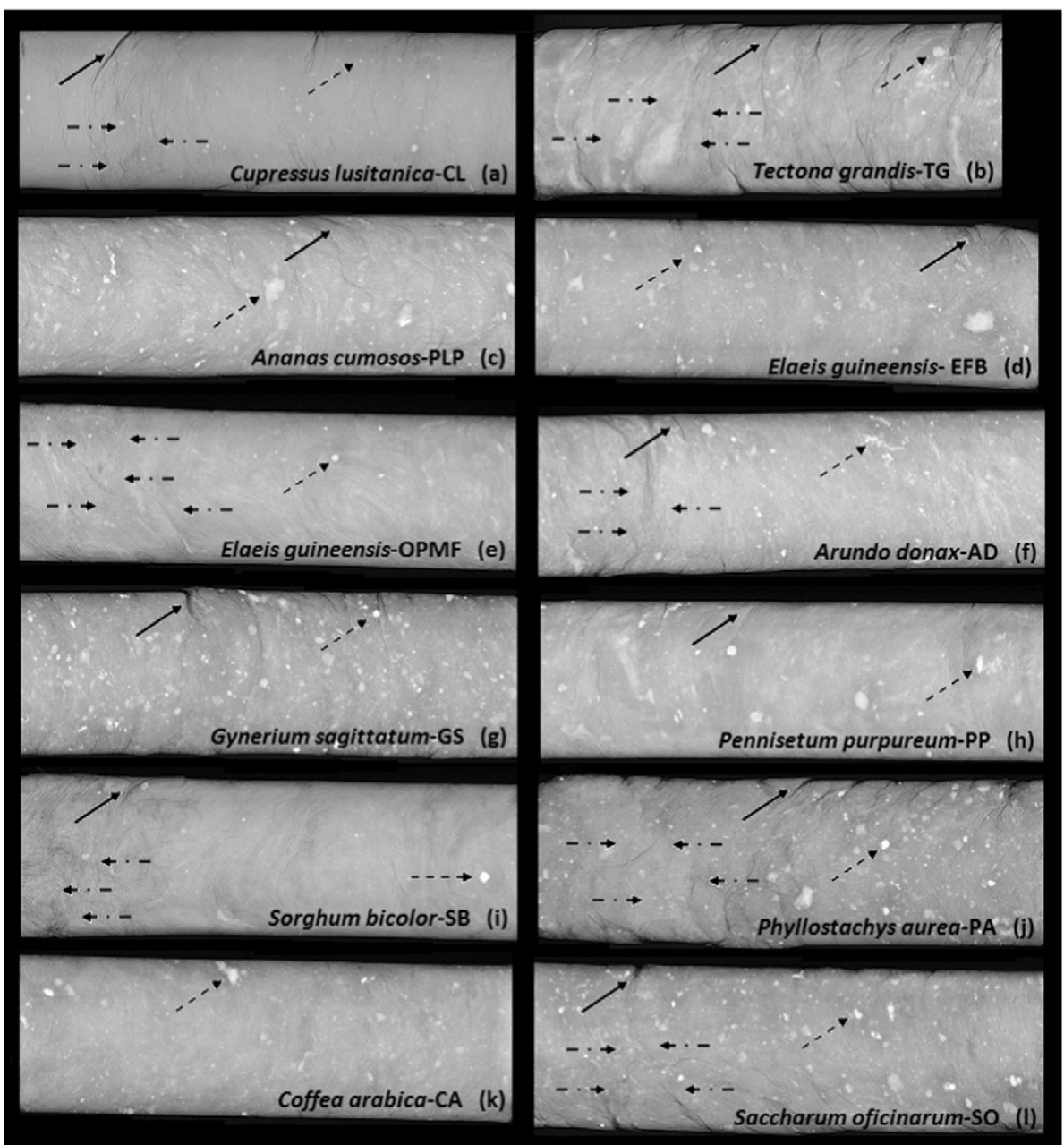

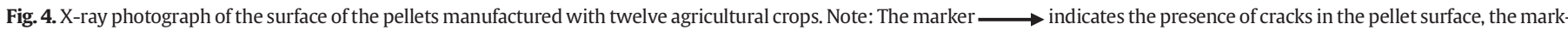
er $-\rightarrow-\rightarrow$ a clear area and the marker $\rightarrow$. $\rightarrow$ the presence of irregularities in the pellet surface. 
Table 3

Density and its variation obtained by X-ray densitometry in transversal and longitudinal directions for twelve pellet crops from Costa Rica.

\begin{tabular}{|c|c|c|c|c|}
\hline \multirow[t]{2}{*}{ Crops } & \multicolumn{2}{|c|}{ Length direction } & \multicolumn{2}{|c|}{ Transversal direction } \\
\hline & $\begin{array}{l}\text { Average } \\
\left(\mathrm{kg} / \mathrm{m}^{3}\right)\end{array}$ & $\begin{array}{l}\text { Coefficient of variation } \\
(\%)\end{array}$ & $\begin{array}{l}\text { Average } \\
\left(\mathrm{kg} / \mathrm{m}^{3}\right)\end{array}$ & $\begin{array}{l}\text { Coefficient of variation } \\
(\%)\end{array}$ \\
\hline Cupressus lusitanica-CL & $1208^{\mathrm{AF}}$ & $4.3^{\mathrm{BC}}$ & $1208^{\mathrm{ABCDE}}$ & $5.2^{\mathrm{D}}$ \\
\hline Tectona grandis-TG & $1136^{\mathrm{EFI}}$ & $7.0^{\mathrm{AC}}$ & $1136^{\mathrm{DEF}}$ & $7.7^{\mathrm{CD}}$ \\
\hline Ananas comosus-PLP & $1221^{\mathrm{AE}}$ & $6.9^{\mathrm{AC}}$ & $1221^{\mathrm{ABCD}}$ & $16.4^{\mathrm{A}}$ \\
\hline Elaeis guineensis-EFB & $1233^{\mathrm{AC}}$ & $5.0^{\mathrm{BC}}$ & $1233^{\mathrm{ABC}}$ & $11.9^{\mathrm{ABC}}$ \\
\hline Elaeis guineensis-OPMF & $1192^{\mathrm{BCEFG}}$ & $6.4^{\mathrm{AC}}$ & $1192^{\mathrm{BCDE}}$ & $12.7^{\mathrm{ABC}}$ \\
\hline Arundo donax-AD & $1292^{\mathrm{A}}$ & $8.5^{\mathrm{A}}$ & $1292^{\mathrm{A}}$ & $14.1^{\mathrm{AB}}$ \\
\hline Gynerium sagittatum-GS & $1225^{\mathrm{ADG}}$ & $6.3^{\mathrm{AC}}$ & $1225^{\mathrm{ABC}}$ & $8.5^{\mathrm{BCD}}$ \\
\hline Pennisetum purpureum-PP & $1294^{\mathrm{A}}$ & $6.2^{\mathrm{AC}}$ & $1294^{\mathrm{A}}$ & $12.5^{\mathrm{ABC}}$ \\
\hline Sorghum bicolor-SB & $1129^{\mathrm{FJ}}$ & $5.4^{\mathrm{AC}}$ & $1129^{\mathrm{EF}}$ & $9.4^{\mathrm{BCD}}$ \\
\hline Phyllostachys aurea-PA & $1170^{\mathrm{CDEFH}}$ & $6.4^{\mathrm{AC}}$ & $1170^{\mathrm{CDEF}}$ & $8.7^{\mathrm{BCD}}$ \\
\hline Coffea arabica-CA & $1279^{\mathrm{AB}}$ & $4.5^{\mathrm{BC}}$ & $1279^{\mathrm{AB}}$ & $7.1^{\mathrm{CD}}$ \\
\hline Saccharum officinarum-SO & $1096^{\mathrm{HIJ}}$ & $5.0^{\mathrm{BC}}$ & $1096^{\mathrm{F}}$ & $10.3^{\mathrm{BCD}}$ \\
\hline
\end{tabular}

Note: Different letters for each parameter mean statistical significances at $95 \%$.

this in turn results in an increase in density in the region and can be observed as clearer areas, as was the case for the majority of crops herein studied; specifically: PLP, EFB, GS, PA, SO, TG, AD, PP and CA (Fig. 4b-d, f-h, j-l).
A relevant parameter in pellet quality is the presence of surface cracks, since these characterize the susceptibility of pellets to rupture [3]. X-ray photographs of the pellets showed that cracks and irregularities present themselves in different degrees for the majority of crops,

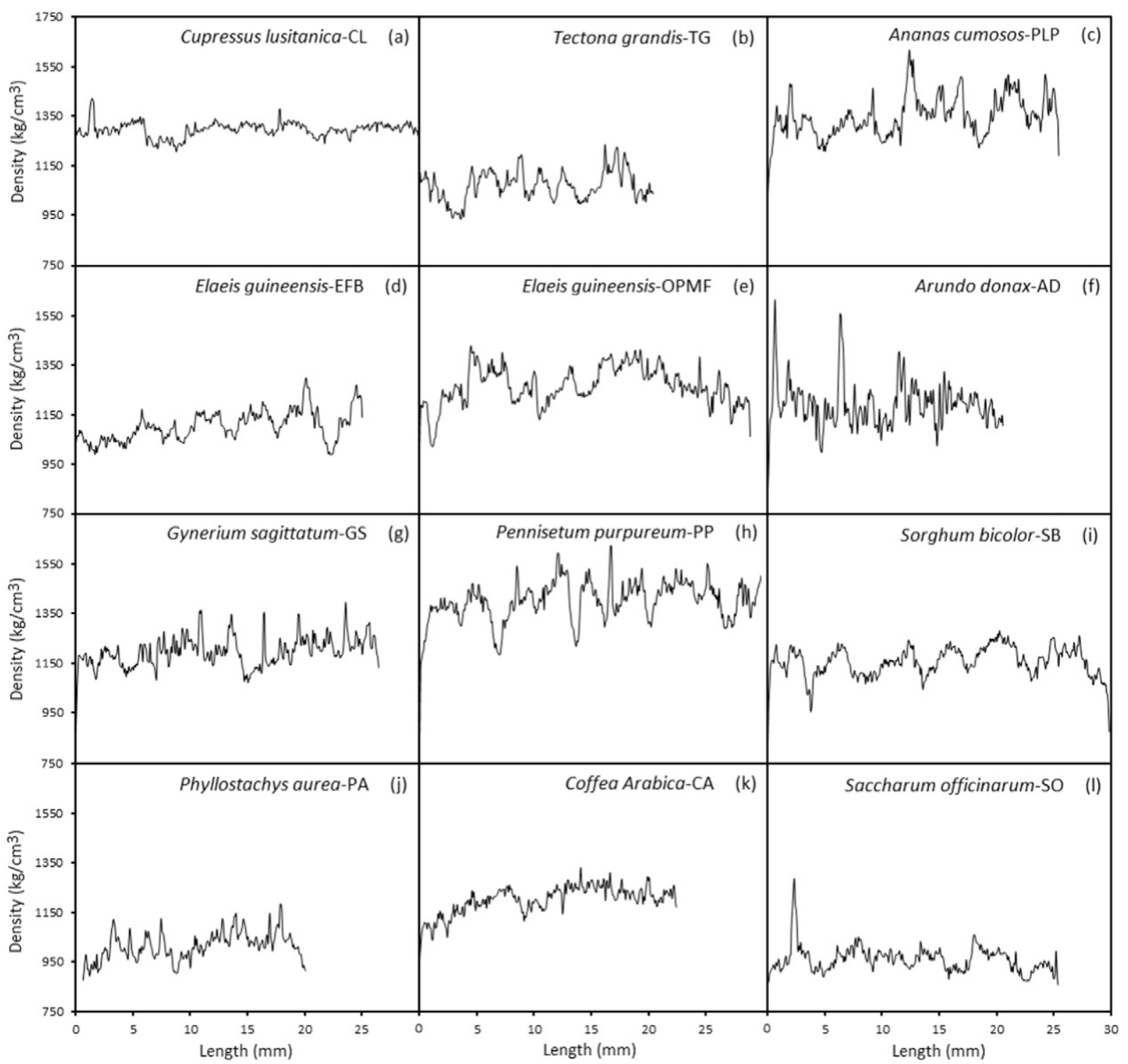

Fig. 5. Longitudinal density variation in twelve pellet crops from Costa Rica. 
with the exception of OPMF and CA where no surface cracks were observed (Fig. 4e, k). Therefore, as expected by Stelte et al. [3], CL, TG, PLP, EFB, AD, GS, PP, SB, PA and SO are crops with cracks, making them susceptible to rupture (Fig. $4 a-d, f-h, j-1$ ). Nevertheless, the results obtained for mechanical durability, which measures the ability of the pellet to remain intact [30] or resistance to compression (Table 3), did not point toward any relation with the presence of cracks. For example, pellets manufactured with EFB, OPMF and PP do not present cracks, but their durability and force at break during compression were one of the lowest (75.54\% and $296 \mathrm{~kg}$, respectively). CL, GS, TG and PA pellets which had the most cracks, only have a low force at break and durability in PA, since TG is one of the most durable crops (92.08\%). According to Temmerman et al. [31] the durability test is a complex test where the rotation factor amply intervenes, and the factor ( $50 \mathrm{rpm})$ recommended by the standard does not reflect the actual pellet durability, therefore they suggest a factor of $105 \mathrm{rpm}$.

\subsection{Density evaluation}

The X-ray densitometry used to evaluate pellet density found that it varies from $1096 \mathrm{~kg} / \mathrm{m}^{3}$ to $1294 \mathrm{~kg} / \mathrm{m}^{3}$ (Table 3) for both longitudinal and transversal directions. However, the variation of density (CVlong and CVtrans) results in differences in the average density of the same crop for both directions. Longitudinally, there are 3 groups present: (i) the group with the highest density values $\left(1221 \mathrm{~kg} / \mathrm{m}^{3}\right.$ to $1294 \mathrm{~kg} / \mathrm{m}^{3}$ ), composed of: PP, AD, CA, EFB, GS and PLP; (ii) a second group with intermediate density $\left(1136 \mathrm{~kg} / \mathrm{m}^{3}\right.$ to $\left.1208 \mathrm{~kg} / \mathrm{m}^{3}\right)$ and composed of: CL, OPMF, PA and TG; and (iii) SB and SO with the lowest

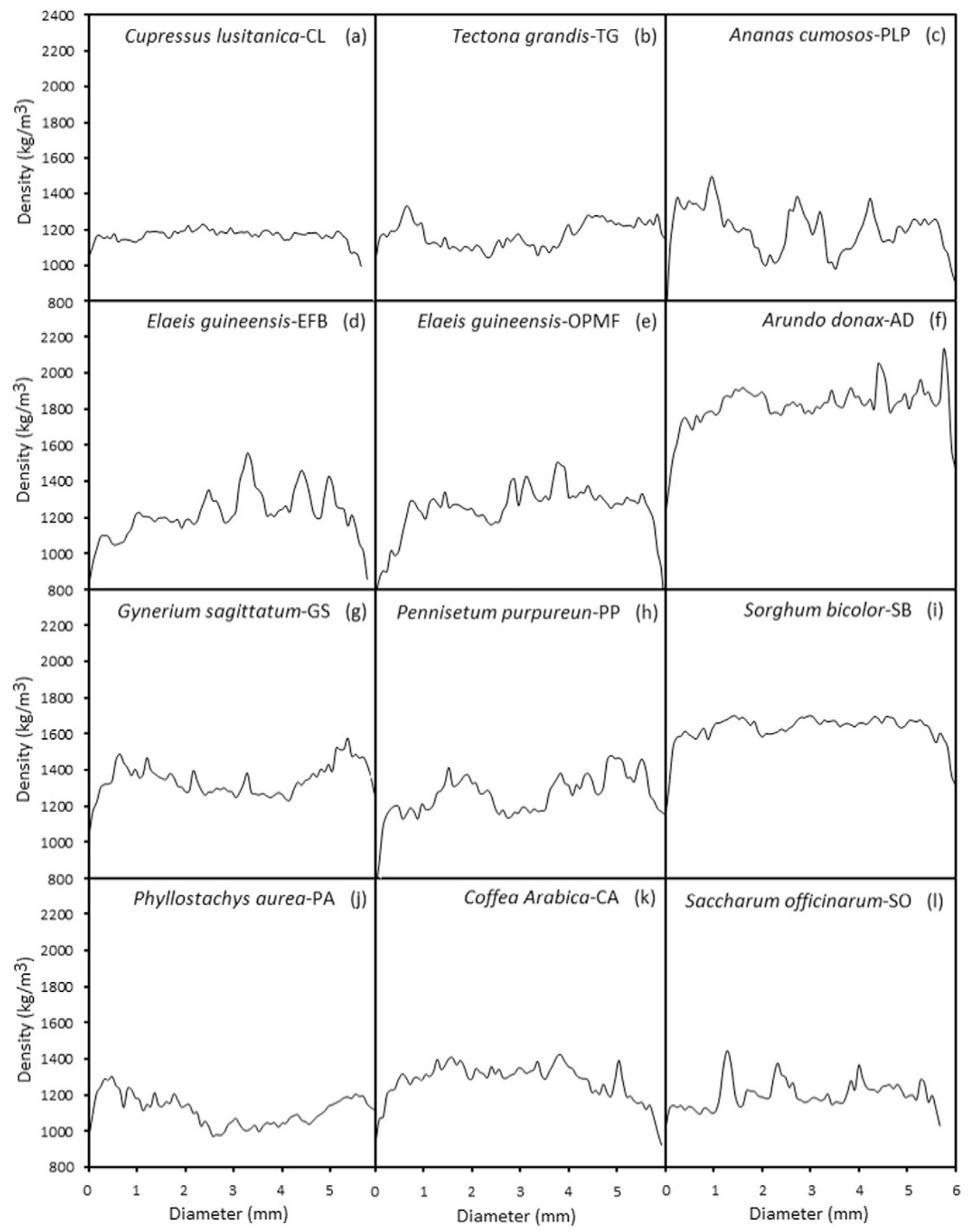

Fig. 6. Transversal density variation in twelve pellet crops from Costa Rica. 
Table 4

Compression effort and mechanical durability of twelve pellet crops from Costa Rica.

\begin{tabular}{|c|c|c|c|}
\hline Crops & Force of break $(\mathrm{N})$ & Compression strength (MPa) & Mechanical durability (\%) \\
\hline Cupressus lusitanica-CL & $738(25.1)^{\mathrm{AB}}$ & $4.80(19.0)^{\mathrm{A}}$ & $84.7(2.0)^{\mathrm{G}}$ \\
\hline Tectona grandis-TG & $394(16.5)^{\text {DEFG }}$ & $2.14(17.2)^{\mathrm{EFG}}$ & $92.1(1.4)^{\mathrm{AD}}$ \\
\hline Ananas comosus-PLP & $359(50.5)^{\text {DEFG }}$ & $1.89(40.9)^{\mathrm{FG}}$ & $91.0(0.6)^{\mathrm{BCDE}}$ \\
\hline Elaeis guineensis-EFB & $563(28.4)^{\mathrm{BCD}}$ & $3.13(29.8)^{\mathrm{CDE}}$ & $92.8(0.7)^{\mathrm{A}}$ \\
\hline Elaeis guineensis-OPMF & $520(34.3)^{\mathrm{BCF}}$ & $2.90(26.6)^{\mathrm{DFH}}$ & $92.8(1.4)^{\mathrm{AB}}$ \\
\hline Arundo donax-AD & $559(9.8)^{\mathrm{BCE}}$ & $3.57(12.6)^{\mathrm{BD}}$ & $93.0(0.5)^{\mathrm{A}}$ \\
\hline Gynerium sagittatum-GS & $676(18.8)^{\mathrm{AC}}$ & $4.67(19.9)^{\mathrm{AB}}$ & $88.4(1.1)^{\mathrm{F}}$ \\
\hline Pennisetum purpureum-PP & $875(19.2)^{\mathrm{A}}$ & $4.17(28.2)^{\mathrm{ABC}}$ & $92.3(1.1)^{\mathrm{AC}}$ \\
\hline Sorghum bicolor-SB & $418(22.5)^{\text {DEFG }}$ & $2.41(25.8)^{\mathrm{EFGH}}$ & $84.5(0.9)^{G}$ \\
\hline Phyllostachys aurea-PA & $444(28.6)^{\text {DEFG }}$ & $2.64(30.5)^{\mathrm{DG}}$ & $72.1(0.5)^{\mathrm{I}}$ \\
\hline Coffea arabica-CA & $297(24.1)^{G}$ & $1.70(25.0)^{G}$ & $75.5(2.1)^{\mathrm{H}}$ \\
\hline Saccharum officinarum-SO & $503(49.5)^{\mathrm{CG}}$ & $2.05(31.6)^{\mathrm{EFG}}$ & $90.4(0.5)^{\mathrm{E}}$ \\
\hline
\end{tabular}

Note: Different letters for each parameter mean statistical significances at $95 \%$. Values between parentheses indicate coefficient of variation.

densities (Table 3). Moreover, it is also possible to make 3 groupings transversally, but with a slight variation in the species that compose them: (i) the first group, which presents the highest density values (1294 kg/m $\mathrm{m}^{3}$ to $1225 \mathrm{~kg} / \mathrm{m}^{3}$ ), composed of: PP, AD, CA, EFB and GS; (ii) a second group with intermediate density $\left(1192 \mathrm{~kg} / \mathrm{m}^{3}\right.$ to $1221 \mathrm{~kg} / \mathrm{m}^{3}$ ) composed of PLP, CL and OPMF; and lastly (iii) PA, TG, SB and SO with values between $1096 \mathrm{~kg} / \mathrm{m}^{3}$ and $1170 \mathrm{~kg} / \mathrm{m}^{3}$ presenting the lowest density (Table 3).

The average density obtained from pellets made of the twelve different crops (from $1096 \mathrm{~kg} / \mathrm{m}^{3}$ to $1294 \mathrm{~kg} / \mathrm{m}^{3}$, Table 3) is in accordance with the range established by the German DIN 51731 standard, from $1000 \mathrm{~kg} / \mathrm{m}^{3}$ to $1400 \mathrm{~kg} / \mathrm{m}^{3}$ [32]. Also, Lehtikangas [33] indicates an average density of $1234 \mathrm{~kg} / \mathrm{m}^{3}$ for pellets manufactured with sawdust obtained from a combination of Picea abies and Pinus silvestris, which is a value found among the higher average density values obtained for PP, AD, CA, EFB, GS and PLP in this study $\left(1221 \mathrm{~kg} / \mathrm{m}^{3}\right.$ to $\left.1294 \mathrm{~kg} / \mathrm{m}^{3}\right)$.

Density is shown by its longitudinal and transversal profiles (Figs. 5 and 6). In both directions of the pellet two density variation patterns were observed: one uniform and another irregular. Density of uniform variability in longitudinal direction was observed in: CL, EFB, CA and SO (Fig. 5a, d, k-1), whereas the other species (TG, PLP, OPMF, AD, GS, $\mathrm{PP}, \mathrm{SB}$ and $\mathrm{PA}$ ) presented an irregular variation pattern (Fig. 5b-c, ej). Transversally, the crops with a uniform pattern were: CL, TG, GS SB, PA and CA (Fig. 6a-b, g, i-k), while PLP, EFM, OPMF, AD, PP and SO presented an irregular pattern (Fig. 6c-f, h, l).

CVlong values (from $4.3 \%$ to $8.5 \%$ ) are lower compared to CVtrans (from $5.2 \%$ to $16.4 \%$ ) (Table 3 ). The lowest CV values found both in longitudinal and transversal directions are CL and CA, while PLP and AD present the highest. No differences were observed for CVlong among the crops, with the exception of $\mathrm{AD}$, which is statistically different from CL, EFB, CA and SO. Likewise, for CVtrans, most crops do not present statistical differences among each other, with the exception of PLP, which presents differences with CL, TG, GS, PP, SB, PA, CA and SO; as well as CL, which is different from PLP, EFB, OPMF and AD (Table 3).

Density evaluation by X-ray densitometry, measured by means of the CVlong and the CVtrans, demonstrated that both transversal and longitudinal direction variations exist for all crops (Table 3 and Figs. 5-6). Crops like CL, EFB, CA and SO with the lowest CVlong, are correlated with uniform density profiles lengthwise on the pellet (Fig. $5 \mathrm{a}, \mathrm{d}$, $\mathrm{k}-\mathrm{l}$ ). Likewise, the low variation in density profile of CL, TG, GS, SB, PA and $C A$ in transversal direction results in lower CVtrans, producing a uniform density profile (Fig. 6a-b, g, i-k).

The particle size of pellets of the crops studied is responsible for the variations observed in the density profile for both longitudinal and transversal directions [27]. In this regard, some studies suggest that the lower the particle size, the higher the pellet density; however, if the particle size is not uniform, density variations may occur [33-36].

The internal density variations are attributed to many factors. Nevertheless, one factor that may be influencing the density variation in this study is that the pellets present clearer areas or spots in their surface
(Fig. 4), which tend to produce areas of greater density in some parts of the pellet, thus affecting its density pattern and resulting, in some cases, in higher CVlong and CVtrans. As mentioned earlier, some crops have cells with thicker walls or regions in which their walls become thicker $[29,30]$, this variation in its anatomical structure affects their density patterns.

In the same way, the internal structure of each crop that was analyzed, as well as the temperature and pressure applied during pelleting, may affect the density performance [27,37]. Gilbert et al. [38] indicate that density increases substantially at temperatures between $14{ }^{\circ} \mathrm{C}$ and $50{ }^{\circ} \mathrm{C}$, while at temperatures above $75^{\circ} \mathrm{C}$ and $95^{\circ} \mathrm{C}$ pellets have a tendency to stabilize their density. Several authors point out a relationship between pressure and pellet density, where density increases exponentially, with an increase in pressure during pellet manufacture, until reaching the maximum density value $[37,39]$.

\subsection{Mechanical properties}

The force at break varied from $297 \mathrm{~N}$ to $875 \mathrm{~N}$ and the compression stress from 1.70 MPa to 4.80 MPa. The values obtained for compression stress and force at break allow to make three crop groupings: (i) crops with the highest force at break and compression stress: PP, CL and GS; followed by (ii) the crops with intermediate values: EFB, OPMF, AD and SP; and finally (iii): PA, SB, TG, PLP and CA as the lowest values (Table 4).

Fig. 7 illustrates this grouping with the curve force vs. deformation. The first species group (PP, CL and GS) tends to reach high force levels (superior to $650 \mathrm{~N}$ ) with low deformation values, and is characterized by presenting very high-sloped curves in the elastic section of the pellet. The second species group (EFB, OPMF and $A D$ ) performed differently

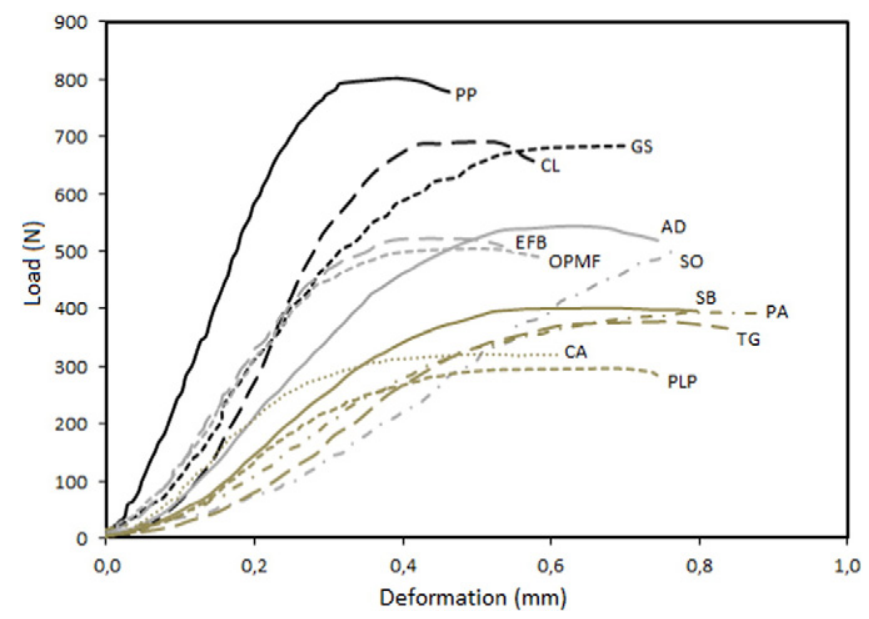

Fig. 7. Force vs. deformation in twelve pellet crops from Costa Rica. 
Table 5

Correlation coefficient ( $r$ ) values between density values and force at break of twelve pellet crops from Costa Rica.

\begin{tabular}{|c|c|c|c|c|}
\hline \multirow[t]{2}{*}{ Crops } & \multicolumn{4}{|l|}{ Density values } \\
\hline & Length direction & Coefficient of variation & Transversal direction & Coefficient of variation \\
\hline Cupressus lusitanica-CL & & $-0.78^{*}$ & & $-0.80^{*}$ \\
\hline Tectona grandis-TG & & $-0.74^{*}$ & & $-0.83^{* *}$ \\
\hline Ananas comosus-PLP & $-0.89^{*}$ & & $-0.89^{*}$ & \\
\hline \multicolumn{5}{|l|}{ Elaeis guineensis-EFB } \\
\hline Elaeis guineensis-OPMF & & $-0.68^{*}$ & & \\
\hline Arundo donax-AD & $-0.70^{*}$ & & $-0.70^{*}$ & \\
\hline Gynerium sagittatum-GS & & $-0.71^{*}$ & & \\
\hline Pennisetum purpureum-PP & & $-0.94^{* *}$ & & $-0.82^{* *}$ \\
\hline Sorghum bicolor-SB & & & & $-0.70^{*}$ \\
\hline Phyllostachys aurea-PA & $-0.83^{* *}$ & $-0.86^{* *}$ & $-0.83^{* *}$ & $-0.73^{*}$ \\
\hline Coffea arabica-CA & & $-0.75^{*}$ & & $-0.74^{*}$ \\
\hline Saccharum officinarum-SO & & & & $-0.86^{* *}$ \\
\hline
\end{tabular}

Note: *statistically significant at $95 \%$ and ${ }^{* *}$ statistically significant at $99 \%$.

due to the fact that the supported force is lower (in the range of $500 \mathrm{~N}$ ) for the same deformation levels as compared with that of the first group. The third species group (PA, SB, TG, PLP and CA) shows lower forces than those of the other two species groups for the same deformation values. Furthermore, their curve slopes are lower in relation to the other species. In turn, SO is a different case, because pellets made of this species can support forces over $500 \mathrm{~N}$, reason for which it is included in the second species group. Nevertheless, at deformation levels of $0.2 \mathrm{~mm}$ or $0.4 \mathrm{~mm}$ it presents forces in the range of the third group species. Moreover, the curve slope for SO is similar to the one of the second group species (Fig. 7).

For the mechanical durability test, values varied from $72.1 \%$ to $93.0 \%$, and the crops with the highest durability values are: $\mathrm{AD}, \mathrm{EFB}, \mathrm{OPMF}, \mathrm{PP}$ and TG, without statistical differences among them, while the rest of the crops (CL, PLP, GS, SB, PA, CA and SO) present lower durability values than the former group and are statistically different among them (Table 4).

Force at break values varied highly (Table 4). The compression resistance trials simulate the compression stress to which pellets are subjected during storage, or when performing. The higher the force at break and compression stress that pellets withstand, the better their final performance [7]. In this respect, García-Maraver et al. [40] point to a force at break of $209.18 \mathrm{~N}$ for pellets manufactured with olive tree branches, value lower than the one obtained for the pellets in this study, which varied from $297 \mathrm{~N}$ to $875 \mathrm{~N}$ (Table 4). However, the compression stress values for different types of biomass have a wide range of values [41] such as the ones presented in this study (Table 4).

With respect to the differences found among pellets from the different crops (Table 4), several studies suggest that pellet production stages, such as drying at high temperatures, milling and pressing, together with the moisture content, affect the final resistance properties of pellets [36-38], as evidenced in this study. The pelletizing process in this study was the same for all crops, although due to characteristics of each crop, different temperature and pressure variations could occur during pellet manufacture, different to those established which affected pellet resistance to compression [3]. Humidity is another factor that may also have an effect in compression resistance values. Compression resistance increases as pellet moisture content decreases [37]. In the present study, efforts were made to keep material at $10 \%$ moisture content before pelleting. However, this was not always possible due to the great capability of the drying equipment used, which did not allow for humidity control.

Durability is defined as the capability of pellets to support destructive forces and pressure during transportation [41,42]. This parameter is considered acceptable when its value is greater than $80 \%$, average when it is between $70 \%$ and $80 \%$, and low when it is less than $70 \%$ [43]. When applying these concepts to the durability obtained in the evaluation of pellets made from the twelve crops, it is possible to observe that the majority (CL, TG, PLP, EFB, OPMF, AD, GS, PP, SB and SO) possess an acceptable durability of $72.12 \%$ and $75.54 \%$, considered of average durability (Table 4). Moreover, it is important to note that crops were not found to have low durability. The acceptable and average durability values obtained for the crops evaluated suggest that pellets will be of good performance. As Temmerman et al. [31] mention, high durability values result in decreased risks associated to fire explosions during pellet transportation or storage as well as with dust emissions, and it avoids problems in the pellet feeding systems.

On the other hand, the differences found among durability values between crops (Table 4 ) may be explained by once more taking into consideration moisture content and particle size. Durability has been reported to increase as pellet moisture content increases [43,44], until reaching an optimum point which, once it has been surpassed, pellet

Table 6

Multiple stepwise correlation analysis for the correlation between density values and force at break of twelve pellet crops from Costa Rica.

\begin{tabular}{|c|c|c|c|c|c|}
\hline \multirow[t]{2}{*}{ Crops } & \multirow[t]{2}{*}{ Correlation coefficient } & \multicolumn{4}{|l|}{ Density values } \\
\hline & & Length direction & Coefficient of variation & Transversal direction & Coefficient of variation \\
\hline Cupressus lusitanica-CL & $\mathrm{R}=0.87$ & $0.12(0.75)$ & $0.63^{*}\left(0.63^{*}\right)$ & - & - \\
\hline Tectona grandis-TG & $\mathrm{R}=0.90$ & - & - & - & - \\
\hline Ananas comosus-PLP & $\mathrm{R}=0.68$ & - & - & - & - \\
\hline Elaeis guineensis-EFB & $\mathrm{R}=0.69$ & - & - & - & - \\
\hline Elaeis guineensis-OPMF & $\mathrm{R}=0.68$ & - & - & - & $0.47^{*}\left(0.47^{*}\right)$ \\
\hline Arundo donax-AD & $\mathrm{R}=0.70$ & - & - & $0.50^{*}\left(0.50^{*}\right)$ & - \\
\hline Gynerium sagittatum-GS & $\mathrm{R}=0.77$ & - & $0.09(0.59)$ & - & $0.50^{*}\left(0.50^{*}\right)$ \\
\hline Pennisetum purpureum-PP & $\mathrm{R}=0.94$ & - & $0.02(0.90)$ & - & $0.88 *(0.88 *)$ \\
\hline Sorghum bicolor-SB & $\mathrm{R}=0.70$ & - & $0.49^{*}\left(0.49^{*}\right)$ & - & - \\
\hline Phyllostachys aurea-PA & $\mathrm{R}=0.90$ & - & - & - & - \\
\hline Coffea arabica-CA & $\mathrm{R}=0.81$ & $0.09(0.65)$ & - & - & $0.56^{*}\left(0.56^{*}\right)$ \\
\hline Saccharum officinarum-SO & $\mathrm{R}=0.86$ & - & $0.72^{*}\left(0.72^{*}\right)$ & - & - \\
\hline
\end{tabular}

Note: * statistically significant at 95\%. Values: contribution of the parameter to the coefficient of determination; values between parenthesis: multiple coefficient of determination. 
durability and resistance decrease [7,8]. Regarding pellet size, generally more durable pellets are produced when working with fine particles $[27,36]$. Although in the present study particle size was not determined, the methodology used for manufacturing pellets was different for some crops (PLP, SO, AD, SB, PP, OPMF and CA), which had to be adjusted through additional stages (cane sugar milling, pre-drying, etc.), as was mentioned earlier. The different pellet manufacturing processes used may have induced variations in particle size for the different crops, which would have affected their durability.
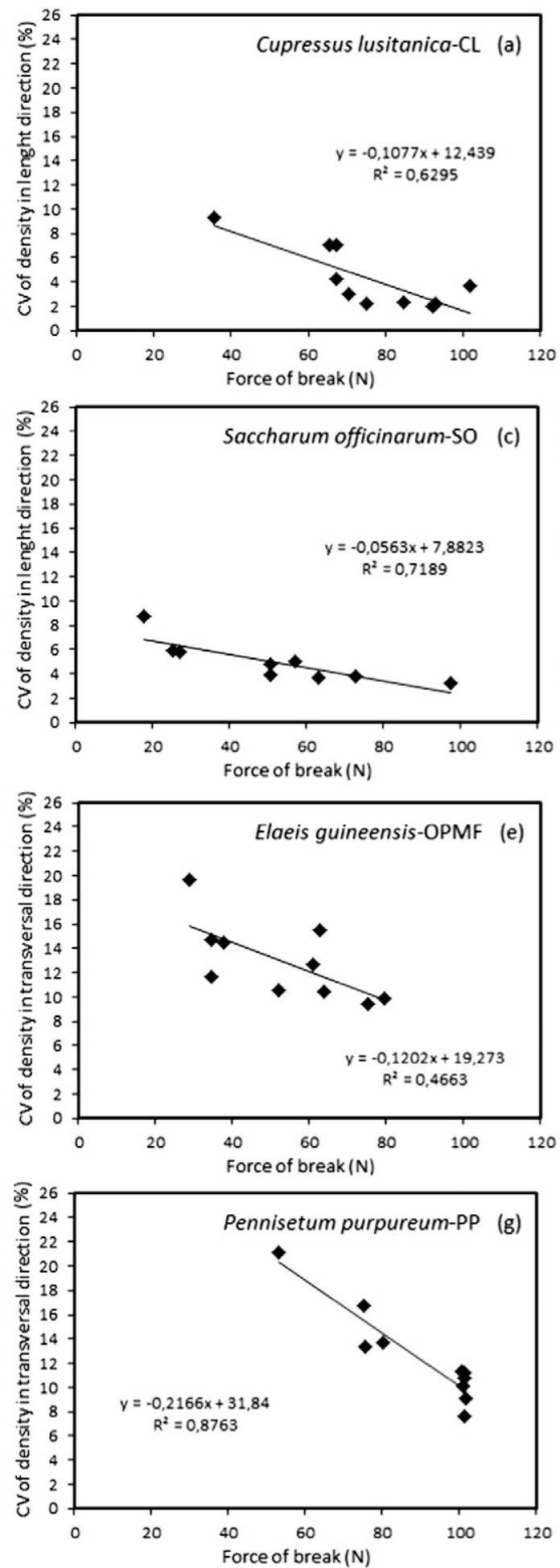

3.4. Relationship between the densitometric values and mechanical durability and compression

Correlation analysis results show that density and mechanical durability correlation values are not significant for any of the twelve crops evaluated. Pearson's correlation coefficients showed that the force at break had a stronger correlation with CVlong and CVtrans with respect to the longitudinal and transversal direction density averages (Table 5). Also, all are negative correlations. CL, TG, PP, PA and CA present a
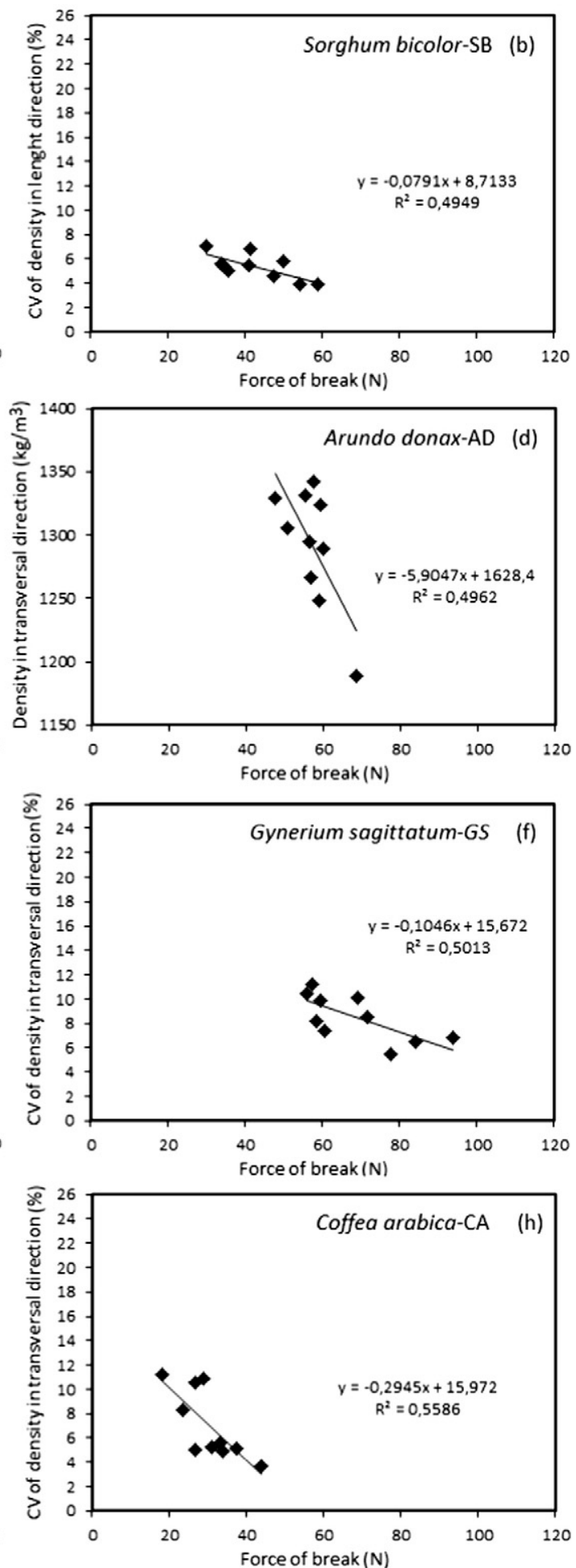

Fig. 8. Relationship for the most significant variable correlations between density values and force at break. 
correlation between the force at break and both coefficients of variation, while OPMF and GS only have force at break and CVlong correlations; SB and SO crops were correlated to CVtrans. PLP, AD and PA were the only crops where the force at break was correlated with the average of both densities. EFB did not present correlation between the density values and the force at break.

From the multiple stepwise correlation analysis it is inferred that CVlong can explain $63 \%$ of the force at break variation in CL, complemented by the longitudinal density average with $12 \%$ of the total variation. Instead, force at break variations in OPMF and AD can only be explained by CVtrans (47\%) and by the transversal direction density average (50\%) respectively (Table 6). Meanwhile, for SB and SO, the force at break was correlated to CVlong in $49 \%$ and $74 \%$ respectively. CVlong explains $9 \%$ and $2 \%$ of the force at break for GS and PP, while CVtrans explains $50 \%$ and $88 \%$ respectively. CVlong explains $74 \%$ of CA's force at break variation. For the remaining crops, no significant correlation was found between the force at break and any of the density values, either in longitudinal or transversal directions (Table 6).

Performance of the force at break density values which showed significant correlations may be noted in Fig. 8 . The force at break increases when CVlong decreases for CL, SB and SO (Fig. 8a-c). OPMF, GS, PP and $\mathrm{CA}$ present the same performance for $\mathrm{CV}$ trans (Fig. $8 \mathrm{e}-\mathrm{h}$ ). For $\mathrm{AD}$, variations in transversal density cause an increase in the force at break (Fig. 8d).

The high amount of crops (CL, TG, OPMF, GS, PP, SB, PA, CA and SO) which presented a negative correlation between the force at break with CVlong and CVtrans (measured by X-ray densitometry) (Table 5), which also explain the greater variation percentage of the force at break (Table 6), as well as the low amount of crops (PLP and AD) which presented correlations between the force at break and the average longitudinal and transversal densities (also measured by X-ray densitometry) (Table 5), suggest that the pellet compression resistance is more related to the density variation that pellets possess both in longitudinal and transversal directions, and that the higher the density variation within the pellet, the lower will be its resistance, or the lower will be the force at break that the pellet can sustain (Fig. 8). This result was confirmed by Carone et al. [45], who found high correlation between pellet density and compression stress in pellets of Olea europaea where, as density increases, the pellet compression resistance also increases.

It is important to highlight that the technique of X-ray densitometry to evaluate density is commonly utilized for studying materials and easily applied in comparison with other techniques that also evaluate pellet quality. It also determines the pellet's mechanical resistance, a key parameter of pellet quality. Values reflected by this technique (average density and variation) show the variations in particle size, crop's internal structure and different factors that intervene in the pelletizing process $[27,37]$. This is therefore a useful technique to ensure quality and final resistance of pellets.

\section{Conclusions}

The use of X-ray photography for pellet quality evaluation shows that it is possible to observe cracks and irregularities, and clearer areas on the surface of the pellets. However, surface cracks and irregularities are not indicators of pellet durability or resistance to compression. Meanwhile, clearer surface areas are associated with high density values in these regions. Additionally, these regions are responsible for producing high variability in the pellet's internal density. The application of this technique showed that pellets fabricated with PLP, EFB, GS, PP and CA have better quality because they are more uniform, low presence of crack and mechanical properties were the highest.

The evaluation of mechanical properties showed that pellet durability and resistance to compression evaluated for the twelve crops can be considered as high, which could warrant their adequate manipulation.
The X-ray densitometry evaluation showed that pellet evaluation by this technique permits the determination of pellet mechanical resistance, a very important quality parameter. The force at break and CVlong and CVtrans were correlated for a high number of the crops evaluated, suggesting that pellet compression resistance is more closely related with pellet density variations both in longitudinal and transversal directions. Therefore low variation in density values suggests that the process of pelletizing is adequate.

\section{Acknowledgment}

The authors wish to thank the Vicerrectoría de Investigación y Extensión at the Instituto Tecnológico de Costa Rica (ITCR), Ingenio Taboga and Ingenio el Viejo, with special thanks to Dr. Fermin Subiros and for the raw materials and facilities for the study.

\section{References}

[1] R. Luque, L. Herrero-Davila, J.M. Campelo, J.H. Clark, J.M. Hidalgo, D. Luna, J.M Marinasa, A.A. Romero, Biofuels: a technological perspective, Energy Environ. Sci. 1 (2008) 542-564.

[2] O.O. Fasina, Physical properties of peanut hull pellets, Bioresource Technology 2008 (99) (2008) 1259-1266

[3] W. Stelte, J.K. Holm, A.R. Sanadi, S. Barsberg, J. Ahrenfeldt, U.B. Henriksen, A study of bonding and failure mechanisms in fuel pellets from different biomass resources, Biomass and Bioenergy 35 (2011) 910-918

[4] M. Stahl, J. Berghel, Energy efficient pilot-scale production of wood fuel pellets made from a raw material mix including sawdust and rapeseed cake, Biomass and Bioenergy 35 (2011) 4842-4854.

[5] K. Theerattananoon, F. Xua, J. Wilsonb, R. Ballardc, L. Mckinneyb, S. Staggenborgc, P. Vadlanib, Z.J. Peid, D. Wang, Physical properties of pellets made from sorghum stalk corn stover, wheat straw, and big bluestem, Industrial Crops and Products 33 (2011) 325-332.

[6] R. Razuan, K.N. Finney, Q. Chen, V.N. Sharifi, J. Swithenbank, Pelletised fuel production from palm kernel cake, Fuel Processing Technology 92 (2011) 609-615.

[7] N. Kaliyan, R.V. Morey, Factors affecting strength and durability of densified biomass products, Biomass and Bioenergy 33 (2009) 337-359.

[8] S.M. Lee, B.J. Ahn, D.H. Choi, G.S. Han, H.C. Jeong, S.H. Ahn, I. Yang, Effects of densification variables on the durability of wood pellets fabricated with Larix kaempferi C. and Liriodendron tulipifera L. sawdust, Biomass and Bioenergy 48 (2013) 1-9.

[9] S. Mani, L.G. Tabil, S. Sokhansanj, Effects of compressive force, particle size and moisture content on mechanical properties of biomass pellets from grasses, Biomass and Bioenergy 30 (2006) 648-654.

[10] N. Kaliyan, R.V. Morey, Natural binders and solid bridge type binding mechanisms in briquettes and pellets made from corn stover and switchgrass, Bioresource Technology 101 (2010) 1082-1090.

[11] M.T. Reza, M.H. Uddin, J.G. Lynam, C.J. Coronella, Engineered pellets from dry torrefied and HTC biochar blends, Biomass and Bioenergy 63 (2014) 229-238.

[12] N. Kotwaliwale, K. Singh, A. Kalne, S.N. Jha, N. Seth, A. Kar, X-ray imaging methods for internal quality evaluation of agricultural produce, Journal of Food Science and Technology 51 (2014) 1-15.

[13] I.U. Bhuiyan, J. Mouzon, F. Forsberg, S.P.E. Forsmo, M. Sjodahl, J. Hedlund, Consideration of X-ray microtomography to quantitatively determine the size distribution of bubble cavities in iron ore pellets, Powder Technology 233 (2013) 312-318.

[14] S.R. Stock, Recent advances in X-ray microtomography applied to materials, International Materials Reviews 53 (2008) 129-138.

[15] H. Polge, Fifteen years of wood radiation densitometry, Wood Science and Technology 12 (1978) 187-196.

[16] M.G. Schinker, N. Hansen, H. Spiecker, High-frequency densitometry - a new method for the rapid evaluation of wood density variations, IAWA Journal 24 (2003) 231-239.

[17] S.J. Sanabria, U. Hilbers, J. Neuenschwander, P. Niemz, U. Sennhauser, H. Thömen, J.L. Wenker, Modeling and prediction of density distribution and microstructure in particleboards from acoustic properties by correlation of non-contact high-resolution pulsed air-coupled ultrasound and X-ray images, Ultrasonics 53 (2013) 157-170.

[18] W. Zhaohui, W. Zehui, R. Xigen, Studies on radial variation in density of moso bamboo using X-ray scanning, Scientia Silvae Sinica 40 (2004) 111-116.

[19] U.L. Belini, J. Fiorelli, H. Savastano Jr., M. Tomazello Filho, Density profile as a tool in assessing quality of new composite, Materials Research 17 (2014) 138-145.

20] W. Ferreira, I. Valle de Oliveira, A.C. De Oliveira, F. D e Souza, M. Tomazelo, X ray densitometry for waste wood briquettes analysis, Scientia Forestalis 40 (2012) $525-536$.

[21] S. Aragón, Production and quality analysis of pellets manufactured from five potential agricultural lignocellulosic crops in the Northern Region of Costa Rica, Tesis de Licenciatura. Escuela de Ingeniería Forestal, Instituto Tecnológico de Costa Rica, 2015. 42 p. (In Spanish).

[22] C. Tenorio, R. Moya, M. Tomazello-Filho, J. Valaert, Quality of pellets made from agricultural and forestry crops in Costa Rican tropical climates, BioResources 10 (2015) 482-498.

[23] N.K. Walker, R.S. Dobb, Calculation of wood density variation from X-ray densitometer data, Wood and Fiber Science 20 (1988) 35-43. 
[24] BSI. DD CEN/TS 15210-1:2005. Solid Biofuels. Methods for the Determination of Mechanical Durability of Pellets and Briquettes. Part 1: Pellets(Milan, Italy.) 2005

[25] K.A. Aarseth, E. Prestlokken, Mechanical properties of feed pellets: Weibull analysis, Biosystems Engineering 84 (2003) 349-361.

[26] E. Oveisi, A. Lau, S. Sokhansanj, C.J. Lim, X. Bi, S.H. Larsson, S. Melin, Breakage behavior of wood pellets due to free fall, Powder Technology 235 (2013) 493-499.

[27] S. Mani, L.G. Tabil, S. Sokhansanj, An overview of compaction of biomass grinds, Powder Handling and Processing 15 (2003) 160-168.

[28] J.D. Payne, Improving quality of pelleted feeds, Milling Feed and Fertilizer 161 (1978) 34-41.

[29] M. Pereira, A. Beraldo, Bambu de corpo e alma, Canal 6, São Paulo, Brazil, 2007.

[30] A. Shatalov, H. Pereira, Papermaking fibers from giant reed (Arundo donax L.) by advanced ecologically friendly pulping and bleaching technologies, BioResources 1 (2006) 45-61.

[31] M. Temmerman, F. Rabier, P.D. Jensen, H. Hartmann, T. Böhm, Comparative study of durability test methods for pellets and briquettes, Biomass and Bioenergy 30 (2006) 964-972.

[32] Deutsches Institut fur normung (DIN), DIN 51731 Testing of Solid Fuels - Compressed Untreated Wood - Requirements and Testing, German National Standard, Germany, 1996.

[33] P. Lehtikangas, Quality properties of pelletised sawdust, logging residues and bark Biomass and Bioenergy 20 (2001) 351-360.

[34] S. Larsson, M. Thyrel, P. Geladi, T. Lestander, High quality biofuel pellet production from pre-compacted low density raw materials, Bioresource Technology 99 (2008) 7176-7182

[35] D. Bergstrom, S. Israelsson, M. Ohman, S.A. Dahlqvist, R. Gref, C. Boman, I. Wasterlund, Effects of raw material particle size distribution on the characteristics of Scots pine sawdust fuel pellets, Fuel Processing Technology 89 (2008) 1324-1329.
[36] C. Serrano, E. Monedero, M. Lapuerta, H. Portero, Effect of moisture content, particle size and pine addition on quality parameters of barley straw pellets, Fuel Processing Technology 92 (2011) 699-706.

[37] C. Rhén, R. Gref, M. Sjostrom, I. Wasterlund, Effects of raw material moisture content, densification pressure and temperature on some properties of Norway spruce pellets, Fuel Processing Technology 87 (2005) 11-16.

[38] P. Gilbert, C. Ryu, V. Sharifi, J. Swithenbank, Effect of process parameters on pelletisation of herbaceous crops, Fuel 88 (2009) 1491-1497.

[39] Z. Husain, Z. Zainac, Z. Abdullah, Briquetting of palm fibre and shell from the processing of palm nuts to palm oil, Biomass and Bioenergy 22 (2002) 505-509.

[40] A. García-Maraver, A.F. Ramos-Ridao, D.P. Ruiz, M. Zamorano, Quality of pellets from olive grove residual biomass, European Association for the Development of Renewable Energies, Environment and Power Quality (EA4EPQ), International Conference on Renewable Energies and Power Quality, Granada, Spain, 2010.

[41] W. Stelte, A.R. Sanadi, L. Shang, J.K. Holm, J. Ahrenfeldt, U.B. Henriksen, Recent developments in biomass pelletization-a review, BioResources 7 (2012) 4451-4460.

[42] L. Tabil, S. Sokhansanj, Process conditions affecting the physical quality of alfalfa pellets, Applied Engineering in Agriculture 12 (1996) 345-350.

[43] Z. Colley, O.O. Fasina, D. Bransby, Y.Y. Lee, Moisture effect on the physical characteristics of switchgrass pellets, American Society of Agricultural and Biological Engineers 49 (2006) 1845-1851.

[44] T. Filbakk, G. Skjevrak, O. Høibø, J. Dibdiakova, R. Jirjis, The influence of storage and drying methods for Scots pine raw material on mechanical pellet properties and production parameters, Fuel Processing Technology 92 (2011) (2011) 871-878.

[45] M.T. Carone, A. Pantaleo, A. Pellerano, Influence of process parameters and biomass characteristics on the durability of pellets from the pruning residues of Olea europaea L. Biomass and Bioenergy 35 (2011) 402-410. 